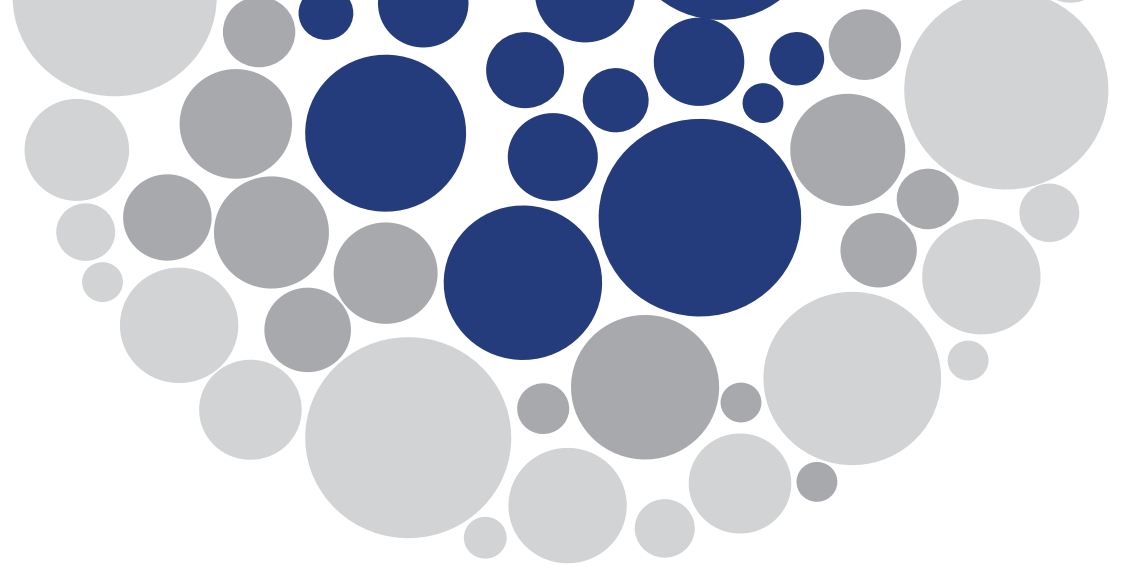

\title{
O Noroeste Fluminense e a atividade leiteira: desafios para a agricultura familiar ${ }^{1}$
}

\author{
Erika Vanessa Moreira Santosa, Samara Venina Simen de Azeredo Silva Chagas \\ Marco Túlio Morais Velasque Silvac \\ a Universidade Federal Fluminense/Programa de Pós-Graduação em Geografia da UFF/CAMPOS, Núcleo de Estudos Rurais \\ e Urbanos (NERU).E-mail: erikamoreira@id.uff.br \\ b Universidade Federal Fluminense/Programa de Pós-Graduação em Geografia da UFF/CAMPOS, Núcleo de Estudos Rurais \\ e Urbanos (NERU). E-mail: samarasimen@id.uff.br \\ c Universidade Federal Fluminense/Curso de Graduação em Geografia (Bacharelado), Núcleo de Estudos Rurais e Urbanos \\ (NERU). E-mail: velasque_marco@id.uff.br
}

\section{Introdução}

A produção leiteira no estado do Rio de Janeiro em 2019 atingiu 432 milhões litros, segundo a Pesquisa Pecuária Municipal, cabendo à mesorregião Sul Fluminense a produção de 130 milhões litros e à região Noroeste Fluminense a produção de 106 milhões de litros. As duas mesorregiões constituem as principais bacias leiteiras do estado e possuem o maior quantitativo de vacas ordenhadas. Todavia, há um déficit entre o consumo e a produção no estado, pois o consumo anual de leite gira em torno de 1,5 bilhão, e a produção é inferior a 500 milhões de litros por ano. Diante desse cenário, programas e políticas públicas têm sido criados para fomentar o incentivo à produção de leite no estado.

Neste texto, o nosso principal objetivo é realizar um panorama da atividade leiteira no Noroeste Fluminense à luz da importância da agricultura familiar, tendo como recorte temporal os anos de 2010 a 2019. Os objetivos secundários visam realizar a contextualização

${ }^{1}$ Este texto é resultado da pesquisa realizada pela equipe com recursos da Pró-Reitoria de Pesquisa, Pós-Graduação e Inovação da Universidade Federal Fluminense (PROPPI/UFF), junto ao Edital FOPESQ/2020. 
da formação socioespacial da região Noroeste Fluminense e compreender os desafios da agricultura familiar diante das políticas públicas. Os procedimentos metodológicos adotados abrangeram levantamento bibliográfico e de dados secundários no Sistema IBGE de Recuperação Automática (SIDRA), na Secretaria Estadual da Fazenda (SEFAZ) e na Empresa de Assistência Técnica e Extensão Rural (EMATER-Rio) e realização de entrevistas semiestruturadas com responsáveis de instituições como EMATER-Rio e Serviço Nacional de Aprendizagem Rural (SENAR).

É importante valorizar a agricultura familiar e destacar as dificuldades enfrentadas na região Noroeste Fluminense, onde, de um lado, há programas e projetos políticos para a sua inserção em um modelo de binômio agricultura-indústria e, de outro, há discursos sempre renegando-a a uma condição de 'região-problema', seja pelos indicadores sociais e econômicos, seja pela perda populacional em alguns municípios, como Laje de Muriaé, Miracema, Natividade e Itaocara.

Para a construção deste texto, organizamos as ideias em quatro seções, além desta introdução e das considerações finais. A primeira seção faz uma contextualização histórica da atividade leiteira no Brasil e no Rio de Janeiro. A seção seguinte é voltada para uma caracterização da região Noroeste Fluminense. A terceira seção apresenta o percurso da atividade leiteira na região Noroeste Fluminense. E, por último, mas não menos importante, a quarta seção analisa o papel das instituições e das políticas públicas de fomento à atividade leiteira e os desafios para a agricultura familiar.

\section{A atividade leiteira no Brasil e no Rio de Janeiro}

A pecuária leiteira está presente no país desde o período colonial, sobretudo nas áreas de exploração do ouro em Minas Gerais, e, segundo Prado Junior (2011), era fonte de abastecimento alimentar na exploração das minas. No entanto, existem diferenças entre a pecuária no Sertão do Nordeste, Campos do Sul e Sul de Minas, sendo que, nessa última localidade, há uma significativa exploração da pecuária leiteira e o processamento dos seus derivados (PRADO JUNIOR, 2011; VALVERDE, 1967). Orlando Valverde (1967), no texto "Geografia da pecuária", também destaca que, no século XVI, a criação de gado era proibida até 10 léguas da costa, "salvo na ilha de Joanes e nos Campos dos Goytacazes".

Segundo Santos (2004), antes do século XIX, não existia uma especialização da pecuária leiteira, sendo que a primeira raça introduzida no Brasil foi a turino, trazida de Portugal. Já a raça holandesa só chegou no início do século XX, nas invernadas das cidades de Salvador e Rio de Janeiro.

Até 1920, ano de implantação da Nestlé no Brasil, não havia no país, uma empresa especializada na produção de derivados lácteos e as duas maiores cidades da época Rio de Janeiro e São Paulo - realizavam a importação de alguns derivados, como queijo e manteiga europeus. $\mathrm{O}$ aumento do consumo de leite e derivados nessas cidades, consequência do crescimento urbano acelerado das primeiras décadas do século XX, estimulou o Sul de Minas a se transformar na primeira região especializada na produção leiteira no Brasil [...] (SANTOS, 2004, p. 52).

Até os anos 1950, a produção era baixa, se comparada a outros países, como Holanda e França, ou seja, a produção era de 2 litros por vaca. Outrossim, o consumo de leite e seus derivados também era baixo, pois a produção era de alto custo, e "o seu preço 
é artificialmente elevado pelas empresas e cooperativas que exploram o comércio" (VALVERDE, 1967, p. 259). A partir de 1950, no pós-guerra, Valverde (2020 [1967]) retrata que a instalação de fábricas no Brasil (Glória, Nestlé, Mococa etc.) reorganizou a produção e ampliou a demanda do leite cru para seu processamento.

A instalação da Nestlé no Brasil ocorreu em 1920, em São Paulo, e, no ano de 1936, a empresa instalou sua fábrica no estado do Rio de Janeiro, no município de Barra Mansa, com a produção de leite pasteurizado, leite condensado e outros derivados lácteos (SANTOS, 2004). Wilkinson (2007, p. 354) destaca que, entre 1940 e 1990, o setor leiteiro brasileiro estava em uma fase de ajustamento à demanda urbano-industrial, com a regulamentação do leite, a pasteurização e, por conseguinte, o surgimento do tipo c (saquinho) e do tipo b. Nos anos 1980, Wilkinson (2007) aponta ainda o aumento da demanda do leite e seus derivados tanto pelo incremento do consumo da classe média urbana como pela atuação de empresas multinacionais.

Com a crise dos anos 1980 e a abertura da economia nos anos 1990, ocorreu o aumento da produção de leite tipo longa vida (UHT). Tal incremento "não foi a inovação em si, mas a capacidade financeira e de agir em âmbito nacional e mesmo internacional que selava a superioridade competitiva da Parmalat, que liderava esta inovação e iria desestruturar o sistema cooperativo" (WILKINSON, 2007, p. 357). Houve, portanto, aquisições e fusões no setor lácteo, lideradas pela Nestlé e Parmalat.

Nos anos 1990, com a implantação do Plano Real e a estabilização econômica, a produção de lácteos exibiu um incremento diante da crescente demanda urbana, do aumento da renda e da integração nacional dos mercados. Segundo Wilkinson (2007), no final dos anos 1990, algumas normatizações foram estabelecidas, tais como a Portaria do Programa Nacional da Qualidade do Leite (1999), a Instrução Normativa no 51 (BRASIL, 2002), entre outras.

O consumo de leite e seus derivados vem aumentando no século XXI. Segundo o estudo de Camilo (2018, p. 5), “[...] a CONAB aponta para um aumento médio per capita de 4,3\% a.a. nos últimos 14 anos, passando de $122 \mathrm{~kg} /$ pessoa/ano em 2000 para $168,2 \mathrm{~kg} /$ pessoa/ano em 2014. Neste ritmo, em 2023, o consumo per capita poderá atingir cerca de $220 \mathrm{~kg} /$ habitante/ano".

Os principais derivados produzidos pela indústria de laticínios brasileira são os queijos (Prato e Mussarela), leite UHT e leite em pó (integral e desnatado). Afirma o IBGE que apenas $70 \%$ do leite produzido vai para a indústria (leite formal), cerca de 24,5 bilhões de litros, sendo que, deste montante, apenas $68 \%$ é inspecionado por órgãos federais. Do total de leite formal, segundo a CONAB (2013), cerca de 70\% (17,4 bilhões de litros) são envasados em forma de leite fresco (Ultra High Temperature - UHT, refrigerado barriga mole), 25\% (6,1 bilhões de litros) são para a produção de queijos e 2,5\% (500 milhões de litros) são destinados à produção de leite em pó (integral e desnatado), o restante, 2,5\% (500 milhões de litros), compõe a produção de cremes, iogurtes, bebidas lácteas e manteiga (CAMILO, 2018, p. 5).

No decurso dessa breve contextualização sobre a atividade leiteira no Brasil, vários agentes foram responsáveis pela reorganização produtiva, seja no tocante ao processamento de lácteos, seja na espacialização da produção. O Estado atuou, outrora, nas questões legislativas e normativas e nos programas de fomento à produção. Segundo Camilo (2018, p. 75), a atuação do Estado na cadeia produtiva do leite acontece em três frentes: 
na produção (fomento à produção e tabelamento), na qualidade dos lácteos (fiscalização e normas) e na demanda/consumo (programas sociais e políticas econômicas).

Os dados da Estatística da Pecuária do Instituto Brasileiro de Geografia e Estatística (2020) mostram, por meio da Figura 1, o comportamento da produção de leite no intervalo de 2015 a 2020 no Brasil.

Mesmo diante da pandemia da Covid-19, a produção de leite ampliou de 6,28 bilhões de litros em 2019 ( $3^{\circ}$ trimestre) para 6,45 bilhões de litros em 2020. Esse aumento da produção se refletiu no incremento do valor pago ao produtor de $\mathrm{R} \$ 1,38$ por litro (2019) para R\$1,94 (2020); todavia, esse valor é médio, e há alterações entre as unidades da federação e nas microrregiões geográficas.

A atividade leiteira no estado do Rio de Janeiro se concentra no Médio Paraíba e no Noroeste Fluminense e é incentivada desde 1977, sendo que, neste século XXI, há três instrumentos normativos sobre os incentivos estaduais à produção de leite: o Decreto $\mathrm{n}^{\circ} 29.042$, de 27 de agosto de 2001; o Decreto n $^{\circ} 41.765$, de 20 de março de 2009 (RIO DE JANEIRO, 2009); e o Decreto no 46.198, de 18 de dezembro de 2017 (RIO DE JANEIRO, 2008).

Segundo rege o Decreto n 29.042/2001 (RIO DE JANEIRO, 2001),

Art. 1 Fica instituído o "Programa de Incentivo do Governo do Estado à Produção de Leite", mediante a concessão de crédito presumido do ICMS ao contribuinte fluminense que adquirir leite produzido no Estado do Rio de Janeiro, diretamente do produtor ou através de usinas de laticínios legalmente estabelecidas neste Estado, correspondente ao percentual de $12,28 \%$ (doze inteiros e vinte e oito décimos por cento), sobre o valor total dessas compras, realizadas a partir de 01 de janeiro de 2002.

No Decreto no 46.198/2017 (RIO DE JANEIRO, 2017):

Art. 10. O estabelecimento industrial poderá creditar-se do valor correspondente ao ICMS incidente nas operações em que promover a saída de produto industrializado derivado de leite, inclusive leite UHT Longa Vida comercializado em caixa, destinado ao contribuinte do imposto, vedado o aproveitamento de quaisquer outros créditos de ICMS, inclusive os referidos nos artigos $1 .{ }^{\circ}, 3 .{ }^{\circ}$ e $4 .{ }^{\circ}$.

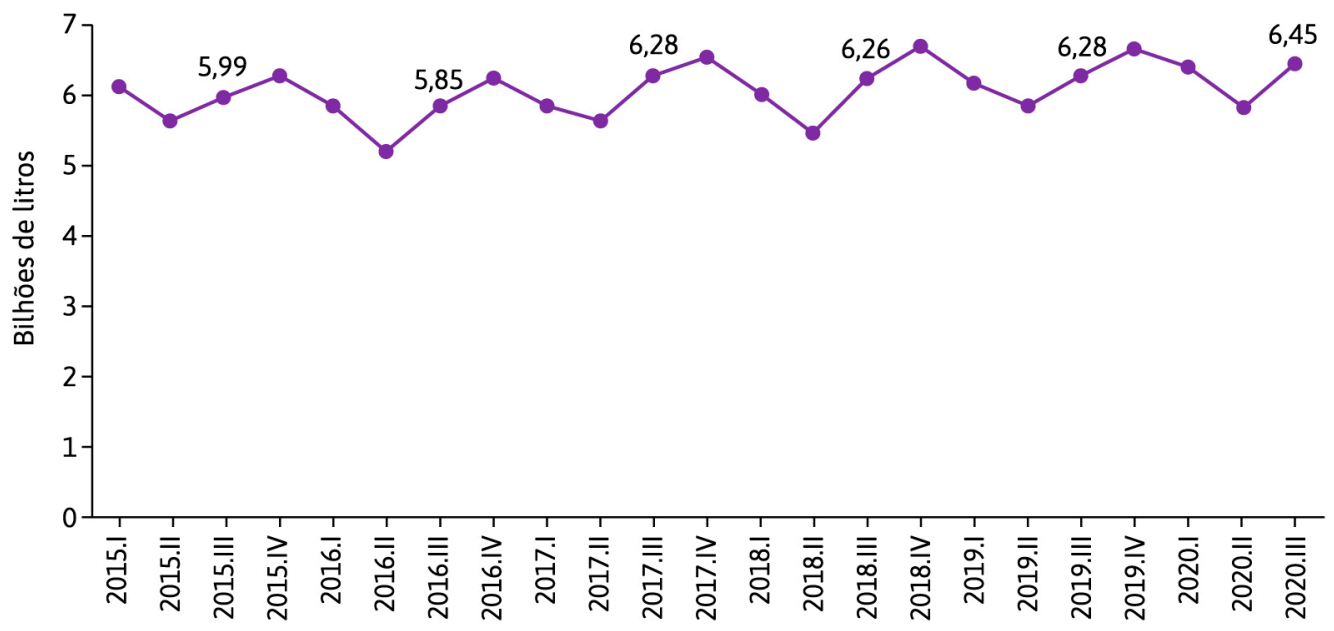

Figura 1 - Aquisição de leite cru por trimestre no Brasil de 2015 a 2020.

Fonte: Estatística da Pecuária do Instituto Brasileiro de Geografia e Estatística (2020). 
$\$ 7 .^{\circ} \mathrm{O}$ crédito de que trata o caput deste artigo somente se aplica quando se tratar de saída de produto lácteo industrializado no Estado do Rio de Janeiro, ainda que a matéria-prima ou insumos utilizados para sua fabricação sejam provenientes de outras unidades federadas, inclusive leite in natura, cru, resfriado ou pasteurizado, transportado a granel.

Em termos de subsídios destinados ao fomento da produção leiteira, a Tabela 1 traz um panorama dos recursos concedidos em valores absolutos deflacionados, por regiões de governo, entre 2007 e 2016, com algumas lacunas em razão da falta de dados nos períodos de 2010 e 2011, segundo a LOAS/RJ.

Entre 2007 e 2016, os recursos aprovados na Lei Orçamentária Anual (LOA) do estado do Rio de Janeiro aumentaram significativamente, e as regiões Médio Paraíba e Noroeste Fluminense passaram a liderar nos valores liberados. $\mathrm{O}$ acumulado nesse período mostra (Figura 2) que o Médio Paraíba recebeu subsídios de R\$ 270 milhões, seguida pelo Noroeste Fluminense, com aproximadamente R 212 milhões, por serem as principais regiões produtoras de leite do estado do Rio de Janeiro (MADANÊLO;

Tabela 1 - Subsídios do estado do Rio de Janeiro para o incentivo à produção de leite, em números absolutos (R\$ milhões) deflacionados, nas regiões de governo.

\begin{tabular}{|lllllllll} 
Região & $\mathbf{2 0 0 7}$ & $\mathbf{2 0 0 8}$ & $\mathbf{2 0 0 9}$ & $\mathbf{2 0 1 2}$ & $\mathbf{2 0 1 3}$ & $\mathbf{2 0 1 4}$ & $\mathbf{2 0 1 5}$ & $\mathbf{2 0 1 6}$ \\
\hline Baixadas Litorâneas & 2,0 & 1,9 & 8,3 & 0,0 & 0,0 & 0,0 & 5,5 & 1,8 \\
\hline Centro-Sul Fluminense & 2,7 & 2,6 & 2,3 & 0,2 & 3,8 & 14,0 & 38,9 & 45,3 \\
\hline Médio Paraíba & 6,6 & 8,4 & 5,1 & 16,0 & 38,6 & 55,8 & 80,1 & 59,2 \\
\hline Metropolitana & 1,3 & 1,1 & 0,0 & 12,8 & 6,0 & 7,3 & 21,4 & 1,4 \\
\hline Noroeste Fluminense & 6,8 & 8,5 & 8,5 & 29,0 & 0,7 & 0,0 & 82,5 & 75,5 \\
\hline Norte Fluminense & 3,7 & 4,9 & 5,3 & 0,7 & 24,8 & 2,4 & 9,0 & 0,0 \\
\hline Região Costa Verde & 0,0 & 0,1 & 1,1 & 0,1 & 0,0 & 0,1 & 0,0 & 0,0 \\
\hline Região Serrana & 3,8 & 4,4 & 2,1 & 13,3 & 24,5 & 5,9 & 43,0 & 37,9 \\
\hline Total & $\mathbf{2 6 , 9}$ & $\mathbf{3 1 , 9}$ & $\mathbf{3 2 , 7}$ & $\mathbf{7 2 , 1}$ & $\mathbf{9 8 , 4}$ & $\mathbf{8 5 , 5}$ & $\mathbf{2 8 0 , 5}$ & $\mathbf{2 2 1 , 2}$
\end{tabular}

Fonte: SEFAZ.

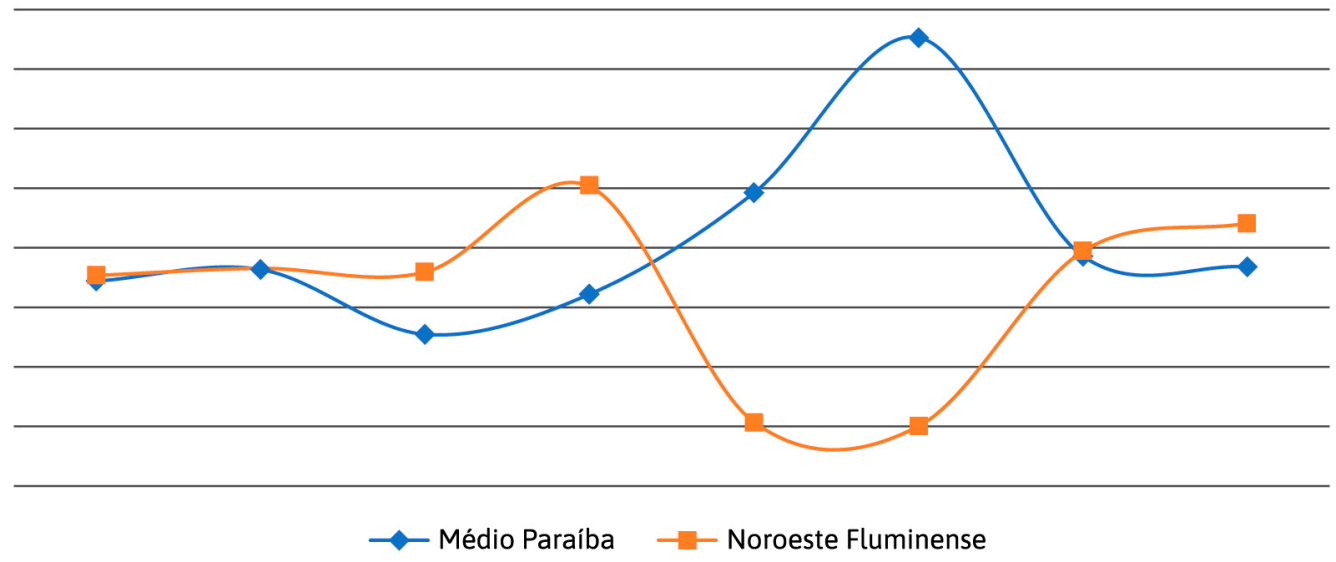

Figura 2 - Subsídios do estado do Rio de Janeiro para o incentivo à produção de leite, em percentuais, nas regiões Médio Paraíba e Noroeste Fluminense. Fonte: SEFAZ. 
MARAFON, 2008, p. 11). Na região Médio Paraíba, está situada a maior cooperativa de leite do estado, a Cooperativa Agropecuária Barra Mansa, com "uma média de 120 mil litros por dia de aproximadamente 1000 associados, dos quais $80 \%$ são pequenos produtores", e uma parte é destinada a Nestlé. Já a região Noroeste Fluminense conta com a segunda maior cooperativa, a Cooperativa Agropecuária de Itaperuna (CAPIL) (MADANÊLO; MARAFON, 2008, p. 11).

Em termos de variação da produção leiteira nos 20 principais municípios fluminenses produtores de leite entre 2010 e 2019, a Tabela 2 e a Figura 3 mostram dois comportamentos opostos: de um lado, a variação positiva em seis municípios, sendo dois da região Noroeste Fluminense (Cambuci e Bom Jesus de Itabapoana); do outro lado, 14 municípios tiveram redução da produção, sendo Itaperuna e Vassouras com maiores variações negativas. A região Noroeste Fluminense, em linhas gerais, é uma bacia leiteira e vem passando por um processo de reorganização produtiva, sendo lócus de ações de instituições públicas e organizações coletivas, algo que será abordado nas seções posteriores.

Tabela 2 - Principais municípios fluminenses com produção da pecuária leiteira, 2010 e 2019, com variação (\%).

\begin{tabular}{lccc}
\hline Municípios & \multicolumn{3}{c}{ Produção de leite (mil litros) } \\
& 2010 & 2019 & Variação (\%) \\
\hline Resende & 18.000 & 30.057 & 66,98 \\
\hline São Francisco de Itabapoana & 10.385 & 16.386 & 57,79 \\
\hline Campos dos Goytacazes & 22.352 & 33.477 & 49,77 \\
\hline Cambuci & 10.700 & 14.890 & 39,16 \\
\hline Bom Jesus do Itabapoana & 15.470 & 16.650 & 7,63 \\
\hline Rio Claro & 12.016 & 12.487 & 3,92 \\
\hline Carmo & 9.244 & 8.953 & $-3,15$ \\
\hline Barra Mansa & 23.106 & 21.857 & $-5,41$ \\
\hline Cantagalo & 16.037 & 14.125 & $-11,92$ \\
\hline Valença & 29.522 & 25.176 & $-14,72$ \\
\hline Santo Antônio de Pádua & 13.948 & 10.508 & $-24,66$ \\
\hline Rio das Flores & 9.914 & 7.411 & $-25,25$ \\
\hline Itaocara & 14.306 & 9.768 & $-31,72$ \\
\hline Natividade & 9.390 & 6.015 & $-35,94$ \\
\hline São Fidélis & 17.840 & 11.020 & $-38,23$ \\
\hline Cachoeiras de Macacu & 7.340 & 4.309 & $-41,29$ \\
\hline Barra do Piraí & 13.982 & 8.157 & $-41,66$ \\
\hline Santa Maria Madalena & 8.926 & 4.865 & $-45,50$ \\
\hline Itaperuna & 28.920 & 13.494 & $-53,34$ \\
\hline Vassouras & 16.238 & 5.960 & $-63,30$ \\
\hline Pan & & & \\
\hline
\end{tabular}

Fonte: Pesquisa Pecuária Municipal (2010 e 2019). 


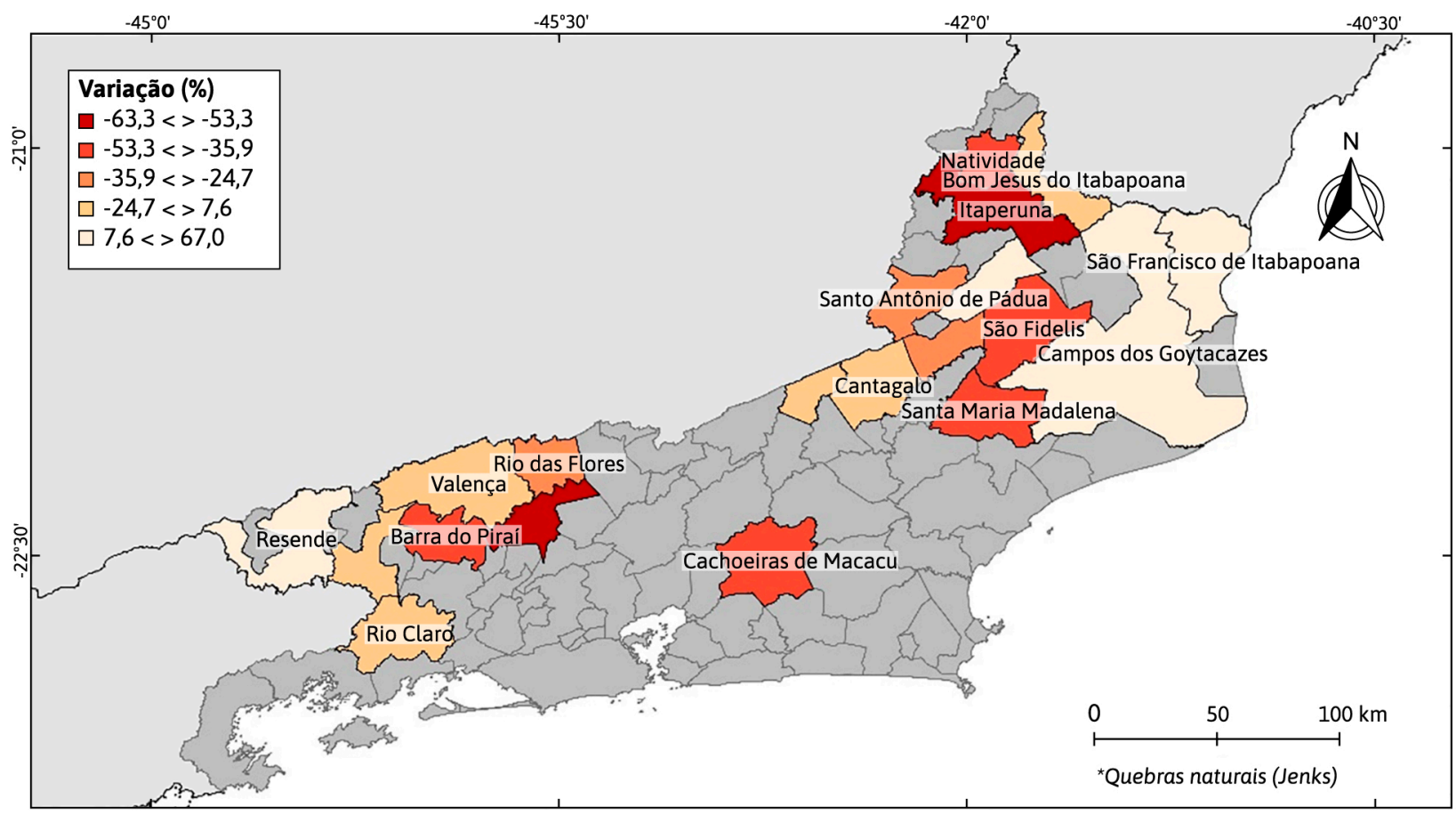

Relação entre a produção de leite (mil litros) de 2010 e de 2019 - 20 maiores produtores do Estado do Rio de Janeiro

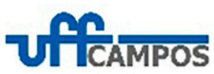

Sistema de coordenadas geográficas Datum SIRGAS2000

Base cartográfica: IBGE, 2019

Fonte: Sistema IBGE de Recuperação Automática

Elaboração: Marco Túlio Moraes Velasque Silva

Figura 3 - A variação da produção de leite (mil litros) nos 20 principais municípios fluminenses produtores (2010-2019).

Fonte: Instituto Brasileiro de Geografia e Estatística (2019).

\section{A região Noroeste Fluminense}

A região Noroeste Fluminense (Figura 4) abarca territorialmente 13 municípios (Aperibé, Cambuci, Italva, Itaperuna, Bom Jesus do Itabapoana, Itaocara, Santo Antônio de Pádua, Varre-Sai, Porciúncula, Natividade, São José de Ubá, Miracema e Laje do Muriaé) e possui uma área de $5.374 \mathrm{Km}^{2}$ (INSTITUTO BRASILEIRO DE GEOGRAFIA E ESTATÍSTICA, 2018).

A cafeicultura era, até os anos 1940, a principal atividade agrícola (GRABOIS et al., 1998; SILVA, 1997, 2006; CRUZ, 1997; 2007; MARINHO, 2017). Diante da crise da atividade, da emergência de novas áreas produtoras mais competitivas e do arrefecimento nas exportações, a cafeicultura foi sendo substituída pela pecuária leiteira. Essas mudanças produtivas refletiram também na estrutura fundiária e na mão de obra, pois, enquanto o café demandava cuidado intensivo, grandes quantitativos de mão de obra (familiar e temporário) e ocupava as pequenas propriedades, a pecuária, em contraposição, era uma atividade extensiva, que não demandava uma participação significativa de mão de obra e abarcava, sobretudo, médias e grandes propriedades (GRABOIS et al., 1998).

Nos anos 1960, segundo Silva (2006, p. 97), a região Noroeste Fluminense "beneficiou-se modestamente dos capitais agroindustriais implementados no território nacional em 


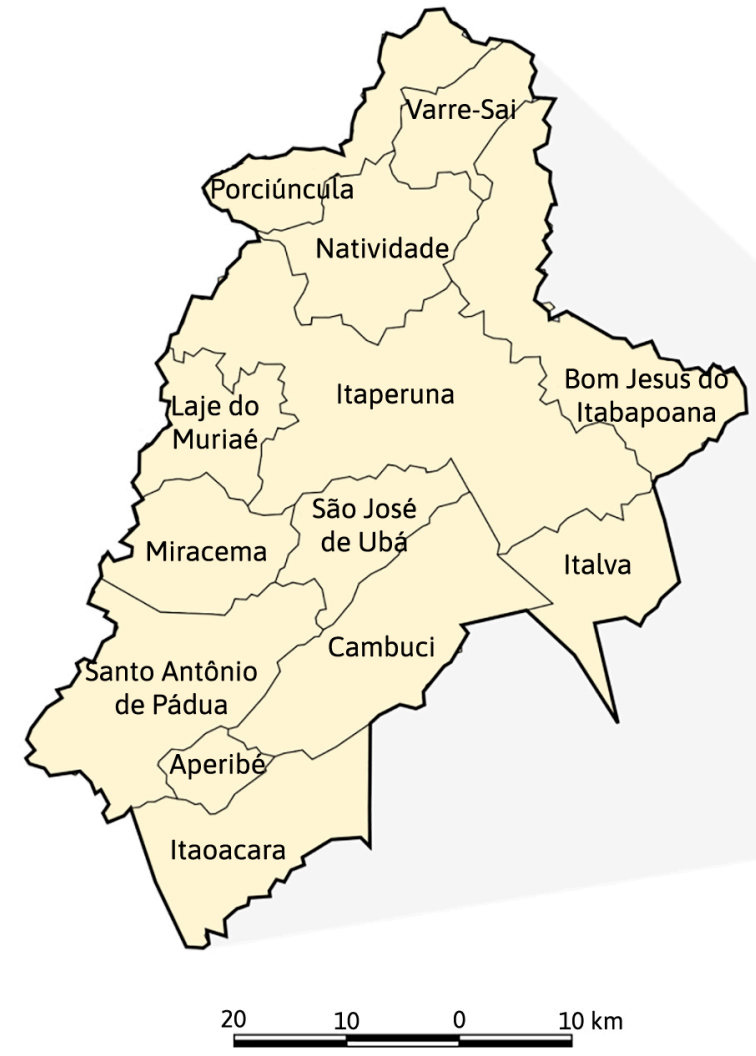

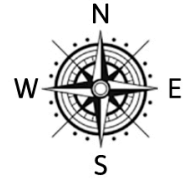

$\mathrm{S}$

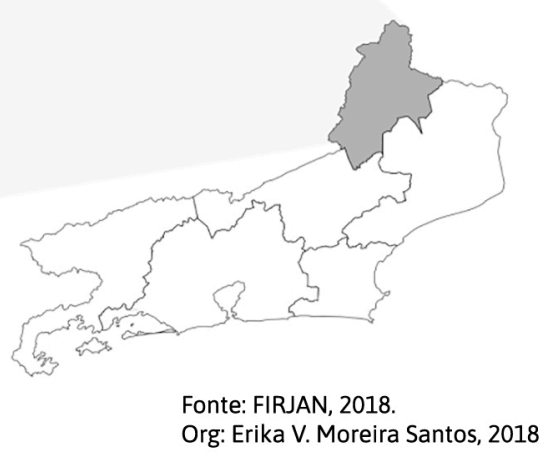

Figura 4 - Localização dos municípios da região Noroeste Fluminense. Fonte: Sistema Firjan (2015).

atendimento à demanda de um mercado urbano fortalecido tanto no Brasil quanto no exterior". No ano de 1961, houve, segundo o autor, a articulação entre a Leite Glória e a Fleischmann \& Royal, e tal estratégia “[...] projetou o Noroeste além dos seus limites político-administrativos, cunhando-se, no imaginário da população fluminense, a identificação emblemática: Noroeste Fluminense: tradicional região leiteira" (SILVA, 2006, p. 97). No final dos anos 1980 e início dos anos 1990, a região passou por crise no setor leiteiro por conta da competitividade com outras bacias leiteiras e da própria estagnação econômica que o país enfrentava naquele contexto.

Segundo Cruz (2007, p. 1), a região Noroeste Fluminense foi "criada em 1987 pelo desmembramento da região Norte Fluminense e na busca de uma 'independência' com relação a Campos dos Goytacazes, que monopolizava a atenção e os recursos da iniciativa privada e dos governos estadual e federal". No final dos anos 1990, foi institucionalizada a regionalização do estado do Rio de Janeiro, pautada nas equivocadas "vocações", sendo o Noroeste Fluminense classificado dentro da vocação para o complexo agropecuário representado por culturas modernas destinadas à exportação ou às indústrias processadoras de alimentos, principalmente nos setores de carne, leite, frutas e leguminosas (MARINHO, 2017, p. 12).

O processo de êxodo rural na região Noroeste Fluminense foi intensificado com a crise da cafeicultura nos anos 1960/70, levando à saída da população rural para o mercado 
de trabalho urbano nas principais cidades da região - Itaperuna e Santo Antônio de Pádua -, pois a produção de café era intensiva em mão de obra (GRABOIS et al., 1998). A população rural, nos últimos anos, reduziu em quase $50 \%$, ao passo que a população urbana aumentou consideravelmente (Tabela 3). Contudo, nos municípios de São José de Ubá e Laje do Muriaé, o fenômeno que vem acontecendo é o de esvaziamento populacional, ou seja, a saída tanto da população rural quanto urbana para outros municípios.

No tocante à estrutura fundiária, a maioria dos municípios teve ampliação tanto do número de estabelecimentos agropecuários quanto da área ocupada, com destaque para Itaperuna e São José de Ubá. Em contrapartida, houve redução de número de estabelecimentos e da área ocupada em Laje do Muriaé. Apenas Natividade teve um movimento de redução da área ocupada, mas uma ampliação significativa de estabelecimentos.

A pecuária está presente majoritariamente nos estabelecimentos familiares, todavia deve-se considerar a relação do tamanho da área com o número de animais, pois há uma relação desigual nesse quesito. Em termos de número de estabelecimentos, a Tabela 4 retrata o peso significativo de estabelecimentos agropecuários com o desenvolvimento da pecuária, destacando-se Itaocara, Itaperuna e Italva. A pecuária leiteira é uma estratégia de reprodução econômica e social dos agricultores familiares e também um desafio diante das questões políticas e econômicas em que o Noroeste Fluminense está inserido, especialmente a desarticulação de organizações coletivas, a subordinação de empresas de processamento e os reduzidos recursos para fomentar a atividade leiteira junto à agricultura familiar.

Tabela 3 - Dinâmica populacional dos municípios da região Noroeste Fluminense, entre 1991 e 2010, segundo a situação de domicílio.

\begin{tabular}{|lcccccc|}
\hline Municípios & \multicolumn{2}{c}{1991} & \multicolumn{2}{c}{2000} & \multicolumn{2}{c}{2010} \\
& Rural & Urbana & Rural & Urbana & Rural & Urbana \\
\hline Aperibé & & & 1.176 & 6.842 & 1.335 & 8.878 \\
\hline Bom Jesus do Itabapoana & 8.693 & 21.180 & 6.230 & 27.425 & 5.484 & 29.927 \\
\hline Cambuci & 11.649 & 9.362 & 4.724 & 9.946 & 3.535 & 11.292 \\
\hline Italva & 6.412 & 6.352 & 4.010 & 8.611 & 3.821 & 10.242 \\
\hline Itaocara & 9.439 & 13.494 & 7.075 & 15.928 & 5.573 & 17.326 \\
\hline Itaperuna & 16.258 & 61.742 & 9.856 & 76.864 & 7.743 & 88.368 \\
\hline Laje do Muriaé & 3.660 & 3.804 & 2.285 & 5.624 & 1.850 & 5.637 \\
\hline Miracema & 4.137 & 20.954 & 3.307 & 23.757 & 2.102 & 24.741 \\
\hline Natividade & 9.629 & 12.136 & 3.384 & 11.741 & 3.036 & 12.046 \\
\hline Porciúncula & 5.026 & 9.535 & 4.075 & 12.018 & 3.870 & 13.890 \\
\hline Santo Antonio de Pádua & 28.025 & 11.575 & 9.277 & 29.415 & 9.489 & 31.100 \\
\hline São José de Ubá & & & 4.087 & 2.326 & 3.905 & 3.098 \\
\hline Varre-Sai & & & 3.722 & 4.132 & 3.685 & 5.790 \\
\hline Total & 102.298 & 170.134 & 63.208 & 234.629 & 55.428 & 262.335 \\
\hline
\end{tabular}

Fonte: IBGE (Censos 1991, 2000 e 2010). 
Tabela 4 - Estabelecimentos agropecuários (familiar e não familiar) com desenvolvimento da pecuária, em 2017, nos municípios da região Noroeste Fluminense.

\begin{tabular}{|lcc|}
\hline Municípios & 2017 & \\
& No estab não familiar & $\mathbf{N}^{\circ}$ estab familiar \\
\hline Aperibé & 75 & 178 \\
\hline Bom Jesus do Itabapoana & 387 & 568 \\
\hline Cambuci & 288 & 765 \\
\hline Italva & 124 & 275 \\
\hline Itaperuna & 610 & 929 \\
\hline Itaocara & 351 & 975 \\
\hline Laje do Muriaé & 103 & 228 \\
\hline Miracema & 209 & 164 \\
\hline Natividade & 240 & 397 \\
\hline São José do Ubá & 194 & 316 \\
\hline Santo Antonio de Pádua & 402 & 659 \\
\hline Porciúncula & 123 & 294 \\
\hline Varre-Sai & 106 & 227 \\
\hline
\end{tabular}

Fonte: Censo Agropecuário (2017).

\section{A atividade leiteira no Noroeste Fluminense}

Para subsidiar nossa análise sobre a atividade leiteira no Noroeste Fluminense, tomamos como base Silva (2006), Grabois et al. (1998), Madanêlo e Marafon (2008), Braga (2008) e Santos (2019). Esse percurso teórico permite compreender como a região vem sendo reorganizada produtivamente a partir de estratégias espaciais de agentes econômicos e políticos.

Desde a década de 1960, a região Noroeste Fluminense tem apresentado certa expressividade na pecuária leiteira. Em 1976, a Fleischmann \& Royal passou a deter o controle acionário da agroindústria local, gerenciando, diretamente, o beneficiamento da produção regional de leite (SILVA, 1997, p. 59), o que levou a Cooperativa Agropecuária de Itaperuna (CAPIL) a exigir de seus associados um "aumento da qualidade da matéria-prima a ser beneficiada. Sob essa nova dinâmica regional, a cooperativa incentivou os seus cooperados a entrarem nas linhas de crédito agrícola", com o objetivo de aumentar a produtividade (SILVA, 1997, p. 59). Madanêlo e Marafon (2008, p.13) apontam que a CAPIL ficou subordinada à Parmalat a partir de 2001, "pondo fim à gestão da Kraft Foods International" 2 . Em 2003, a Parmalat apresentou problemas financeiros, o que levou à "consequente desestabilização da cooperativa e de seus 1.250 associados do Noroeste do estado". Isso resultou em uma crise para a CAPIL e para os produtores de leite, em sua maioria de pequeno porte e com base na mão de obra familiar (MADANÊLO; MARAFON, 2008).

Dos 13 municípios do Noroeste Fluminense, apenas quatro - Varre-Sai, Cambuci, Aperibé e Bom Jesus do Itabapoana - apresentam variação positiva da produção de leite no período de 2010 e 2019, como mostra a Tabela 5 e a Figura 5. E os principais

\footnotetext{
${ }^{2}$ Para maiores detalhamento dessa gestão territorial, ver trabalhos de Silva (2006) e Braga (2008).
} 
Tabela 5 - Variação da produção de leite (mil litros) nos municípios da região Noroeste Fluminense, 2010 e 2019

\begin{tabular}{|lccc|}
\hline Municípios & \multicolumn{3}{c|}{ Produção de leite (mil litros) } \\
& $\mathbf{2 0 1 0}$ & $\mathbf{2 0 1 9}$ & Variação (\%) \\
\hline Varre-Sai & 3.710 & 6.910 & 86,25 \\
\hline Cambuci & 10.700 & 14.890 & 39,16 \\
\hline Aperibé & 2.222 & 2.600 & 17,01 \\
\hline Bom Jesus do Itabapoana & 15.470 & 16.650 & 7,63 \\
\hline Laje do Muriaé & 4.418 & 4.022 & $-8,96$ \\
\hline Italva & 5.750 & 4.804 & $-16,45$ \\
\hline Miracema & 6.935 & 5.497 & $-20,74$ \\
\hline Santo Antonio de Pádua & 13.948 & 10.508 & $-24,66$ \\
\hline Itaocara & 14.306 & 9.768 & $-31,72$ \\
\hline Porciúncula & 7.954 & 5.300 & $-33,37$ \\
\hline Natividade & 9.390 & 6.015 & $-35,94$ \\
\hline São José do Ubá & 10.250 & 5.500 & $-46,34$ \\
\hline Itaperuna & 28.920 & 13.494 & $-53,34$ \\
\hline
\end{tabular}

Fonte: Produção Pecuária Municipal (2010 e 2019).

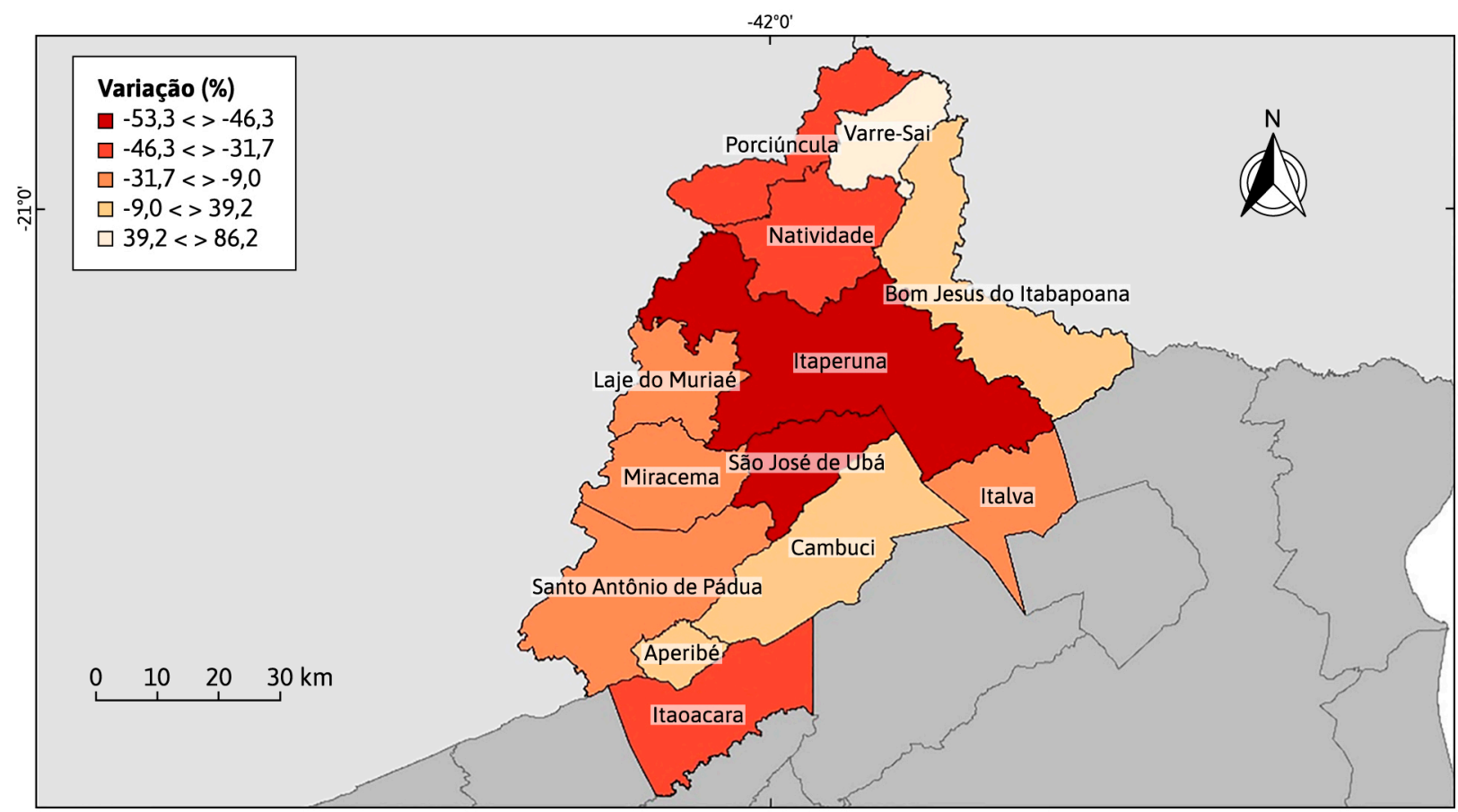

Relação entre a produção de leite (mil litros) de 2010 e de 2019 - 20 maiores produtores do Estado do Rio de Janeiro

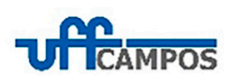

\section{Sistema de coordenadas geográficas Datum SIRGAS2000 \\ Base cartográfica: IBGE, 2019}

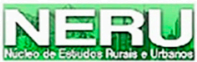

Fonte: Sistema IBGE de Recuperação Automática

Elaboração: Marco Túlio Moraes Velasque Silva

Figura 5 - Variação da produção de leite (mil litros) nos municípios da região Noroeste Fluminense, 2010 e 2019.

Fonte: Produção Pecuária Municipal. 
Tabela 6 - Número de estabelecimentos agropecuários que produzem derivados lácteos internamente, nos municípios da região Noroeste Fluminense, 2006 e 2017.

\begin{tabular}{|lcc|}
\hline Município & $\mathbf{2 0 0 6}$ & $\mathbf{2 0 1 7}$ \\
& $\mathbf{N}^{\circ}$ de estab. & $\mathbf{N}^{\circ}$ de estab. \\
\hline Aperibé & 0 & 4 \\
\hline Bom Jesus do Itabapoana & 3 & 15 \\
\hline Cambuci & 2 & 13 \\
\hline Italva & 0 & 8 \\
\hline Itaperuna & 2 & 43 \\
\hline Itaocara & 16 & 44 \\
\hline Laje do Muriaé & 1 & 13 \\
\hline Miracema & 4 & 9 \\
\hline Natividade & 3 & 14 \\
\hline São José do Ubá & 1 & 4 \\
\hline Santo Antonio de Pádua & 3 & 26 \\
\hline Porciúncula & 7 & 22 \\
\hline Varre-Sai & 12 & 4 \\
\hline Total & 54 & 219 \\
\hline
\end{tabular}

Fonte: IBGE (Censos agropecuários de 2006 e 2017).

municípios que se destacam como os maiores produtores de leite são Itaperuna, Bom Jesus de Itabapoana, Cambuci e Santo Antônio de Pádua.

No Censo Agropecuário de 2006, a região possuía 54 estabelecimentos rurais, que, além da produção do leite cru, também produziam manteiga, queijos e requeijão. Já o Censo Agropecuário de 2017 apontou um aumento para 219 estabelecimentos (Tabela 6). A relação das agroindústrias e os agricultores familiares está pautada em dois vetores importantes (GAZOLLA, 2017, p. 187): 1) relações sociais de proximidade, interconhecimento e relações de confiança; e 2) "presença de economia de escopo na viabilização das agroindústria". As agroindústrias familiares de lácteos são formas de estratégias econômicas e sociais. Esse incremento significativo é resultado de políticas públicas (Pronaf, Balde Cheio, Rio Rural, Decretos de Incentivos à Produção de Leite no estado do Rio de Janeiro, Lei de Isenção do ICMS etc.) e estratégia importante para geração de renda e trabalho diante da crise ocasionada pela falência da Parmalat.

\section{Políticas públicas, instituições e atividade leiteira no Noroeste Fluminense}

A discussão sobre a agricultura familiar vem ganhando legitimidade social, política e acadêmica no Brasil, passando a ser utilizada com mais frequência nos movimentos sociais rurais, pelos órgãos governamentais e por pesquisadores (SCHNEIDER, 2003, p. 99). O agricultor familiar é, sem dúvida, um ator social do mundo moderno, construtor e parceiro de um projeto de sociedade, e não simplesmente objeto de intervenção do Estado, sem história (WANDERLEY, 2004, p. 47). 
Neste contexto, é interessante compreender o espaço rural do Noroeste Fluminense não apenas como um espaço físico de desenvolvimento das atividades agropecuárias, mas à luz da importância da agricultura familiar.

A bovinocultura de leite é um segmento relevante para o desenvolvimento econômico de diversas regiões brasileiras, pois permite a geração de renda e trabalho, reduzindo as pressões sociais e minimizando o desemprego e as questões sociais (EURICH et al., 2016, p. 455).

No Noroeste Fluminense, a bovinocultura de leite recebe apoio de instituições de pesquisa, fomento, capacitação e assistência técnica - como a Empresa de Pesquisa Agropecuária do Estado do Rio de Janeiro (PESAGRO-Rio), o SENAR e a EMATER-Rio e constitui uma atividade imprescindível, atuando na construção de uma economia mais produtiva e socialmente mais justa. Como exemplo, há o Balde Cheio e o Rio Rural, que são políticas públicas vinculadas à estrutura produtiva fluminense.

O projeto "Balde Cheio" coordenado pela Embrapa Pecuária Sudeste, tem como objetivo a transferência de um pacote de conhecimentos e tecnologias para o pequeno produtor de leite e sua capacidade de funcionar como vetor de promoção do desenvolvimento sustentável do agronegócio do leite, compatibilizando a produção local às tendências de produção sustentável em curso no setor internacionalmente (BORGES et al., 2011, p. 152).

Uma das principais estratégias do Balde Cheio são as parcerias firmadas com entidades públicas e privadas, diminuindo a distância entre os institutos de pesquisa e os produtores (EMPRESA BRASILEIRA DE PESQUISA AGROPECUÁRIA, 2008). Além disso, a troca de informações sempre acontece na propriedade rural, na chamada de Unidade Demonstrativa (UD).

Para Schmitz e Santos (2013), a produção leiteira aumenta quando estimulada por políticas públicas, pois objetiva a melhoria na qualidade do leite, padronização essa exigida também pelo setor lácteo (SCHMITZ; SANTOS, 2013, p. 344).

Essas parcerias são importantes, pois, segundo o entrevistado 1, a qualidade do leite é, sem dúvida, a maior dificuldade enfrentada no processamento de lácteos no Noroeste Fluminense. Além disso, existem problemas estruturais que afetam direta e indiretamente produtores e indústrias, tais como: dificuldades de acesso à propriedade por meio de estradas vicinais, deficiência de energia elétrica, questões tributárias, preço do concentrado, questão climática atingindo a produtividade e a qualidade do leite.

Deste modo, uma logística estruturada favoreceria a ampliação da produção, permitindo, inclusive, que a agricultura familiar e a cadeia produtiva do leite ganhassem em competitividade tanto nos principais mercados do estado do Rio de Janeiro quanto na própria região Sudeste.

Já a EMATER-Rio contribui de forma social, assessorando e promovendo a garantia de direitos aos diversos públicos do meio rural e suas organizações por meio da assistência técnica e extensão rural social gratuita (EMPRESA DE ASSISTÊNCIA TÉCNICA E EXTENSÃO RURAL DO ESTADO DO RIO DE JANEIRO, 2021).

Por sua vez, o Programa de Desenvolvimento Rural Sustentável em Microbacias Hidrográficas (Rio Rural) é uma das políticas públicas do Governo do Estado do Rio de Janeiro para o meio rural (RIO RURAL, 2009). De acordo com as considerações de Marinho (2015, p. 79), o Programa abarcou duas etapas: "a primeira denominada Rio 
Rural/GEF - Projeto Gerenciamento Integrado de Agroecossistemas em Microbacias Hidrográficas do Norte e Noroeste Fluminense; e a segunda denominada Rio Rural/BIRD - Projeto de Desenvolvimento Rural Sustentável em Microbacias Hidrográficas do Estado do Rio de Janeiro".

Segundo o entrevistado 2, da EMATER, no município de Italva, localizado no Noroeste Fluminense, foram aplicados $\mathrm{R} \$ 6.260 .000,00$, oriundos do Programa Rio Rural na dimensão ambiental, social e econômica. Isso permitiu que quase 300 hectares de áreas fossem protegidos, georreferenciados e cercados e que todas as associações possuíssem sede própria, trator e arado.

No trabalho Souza et al. (2014), foram avaliados os sistemas de produção organizados em microbacias hidrográficas nos municípios de Itaperuna, Itaocara e Italva. Os resultados mostram uma agropecuária tradicional, em que vários fatores limitaram a eficiência do sistema de produção de leite nas propriedades selecionadas, como manejo alimentar, baixa qualidade do rebanho e das condições tecnológicas.

Para fomentar a bovinocultura, em particular a de leite, o estado buscou implementar, articulado com as esferas federais e municipais, ações estratégicas, programas e políticas públicas. Por exemplo, a Lei no $2.726 / 17$ isenta os setores de laticínios, agroindústria artesanal (até 20 empregados e faturamento anual de até R $\$ 110$ mil UFIRS/RJ), hortifrutigranjeiros e agricultura familiar do recolhimento de 10\% do Fundo Estadual de Equilíbrio Fiscal (FEEF).

Outro programa foi o Prosperar, que buscou ampliar a oferta de emprego e a geração de renda na área rural, apoiando as agroindústrias com a atuação e assistência da EMATER-Rio. Segundo o relatório de atividades da instituição no ano de 2019, as principais ações do Programa tiveram como base legislações sanitárias (Resolução SEAAPI no 510 e n 17 , Resolução SES no 1.779 e Lei $n^{\circ} 4.177$ ), que são mais adequadas a pequenas agroindústrias (EMPRESA DE ASSISTÊNCIA TÉCNICA E EXTENSÃO RURAL DO ESTADO DO RIO DE JANEIRO, 2019).

Por isso, a aplicação de políticas públicas eficientes e a utilização de assistência técnica por parte dos agricultores, contando com a participação deles em cooperativas rurais, levam à geração de renda local.

Todavia, mesmo com essas políticas públicas implementadas, o Noroeste Fluminense é marcado pela concentração de terras e pela desigualdade no acesso aos recursos técnicos e financeiros, sobretudo vinculados à agricultura familiar.

\section{Considerações finais}

A atividade leiteira no Noroeste Fluminense vem sendo uma estratégia de reprodução econômica desde a década de 1960, com a atuação de organizações coletivas e empresas. Não obstante, a atividade tem sido marcada pela desigualdade no acesso aos recursos financeiros e técnicos. Neste trabalho, as inquietações remeteram a entender as questões atinentes ao papel do estado no fomento às ações e políticas para o setor leiteiro da agricultura familiar.

O papel das instituições e entidades é importante para a implementação de políticas públicas de fomento à atividade leiteira, como é o caso da EMATER-Rio, para os projetos de bovinocultura leiteira, Prosperar, Rio Rural e SENAR-Rio, na implementação do 
projeto Balde Cheio. Os escassos recursos financeiros e humanos levam ao esvaziamento das políticas públicas e a um grande desafio para os agricultores familiares, sobretudo em uma região marcada pela concentração fundiária e a redução da população rural.

Se, outrora, a atividade cafeeira foi sendo substituída pela pecuária leiteira, atualmente o agroprocessamento de derivados lácteos vem sendo uma estratégia de geração de renda e trabalho nos estabelecimentos agropecuários familiares, porém carece de mais fomento para sua consolidação.

\section{Referências}

BORGES, M. S.; GUEDES, C. A. M.; ASSIS, R. L. Um estudo do "projeto Balde Cheio" como vetor do desenvolvimento sustentável do pequeno produtor de leite. Revista Brasileira de Agropecuária Sustentável, Viçosa, v. 1, p. 151-161, 2011.

BRAGA, R. M. Gestão do território: o caso da empresa Glória em Itaperuna-RJ (1960-2003). In: MARAFON, G. J.; RIBEIRO, M. A. (Org.). Revisitando o Território Fluminense II. Rio de Janeiro: Gramma, 2008, p. 287-303.

BRASIL. Instrução normativa n 51. Regulamentação, técnica de produção, identificação, coleta e transporte. Diário Oficial da República Federativa do Brasil, Brasília, DF, 2002.

BRASIL. Portaria n ${ }^{\circ}$ 56. Programa Nacional de Qualidade do Leite. Diário Oficial da República Federativa do Brasil, Brasília, DF, 1999.

CAMILO, P. A. A dinâmica geoeconômica da comercialização, logística e transporteda cadeia produtiva do leite na região Sul do Brasil. 2018. Tese (Doutorado em Geografia)-Universidade Federal de Santa Catarina, Florianópolis, 2018.

CRUZ, J. L. V. Desenvolvimento do norte/noroeste fluminense: problematizando o consenso. Vértices, Campos dos Goitacazes, v. 1, n. 1, p. 28-36, 1997.

CRUZ, J. L. V. Os desafios do Norte e do Noroeste Fluminenses frente aos grandes projetos estratégicos. Vértices, Campos dos Goitacazes, v. 9, n. 1-3, p. 43-50, 2007.

EMPRESA BRASILEIRA DE PESQUISA AGROPECUÁRIA - EMBRAPA. Projeto Balde Cheio. São Carlos: Embrapa Pecuária Sudeste (CPPSE), 2008. Folder.

EMPRESA DE ASSISTÊNCIA TÉCNICA E EXTENSÃO RURAL DO ESTADO DO RIO DE JANEIRO EMATER-RIO. Atribuições. 2021. Disponível em: <http://www.emater.rj.gov.br/atribuições >. Acesso em: 25 jan. 2021.

EMPRESA DE ASSISTÊNCIA TÉCNICA E EXTENSÃO RURAL DO ESTADO DO RIO DE JANEIRO EMATER-RIO. Relatórios de atividades. 2019. Disponível em: <http://www.emater.rj.gov.br/relatório. asp>. Acesso em: 18 jan. 2021.

EURICH, J.; WEIRICH NETO, P. H.; ROCHA, C. H. Pecuária Leiteira em uma colônia de agricultores familiares no município de Palmeira Paraná. Revista Ceres, Viçosa, v. 63, n. 4, p. 454-460, 2016.

GAZOLLA, M. Cadeias curtas agroalimentares na agroindústria familiar: dinâmicas e atores envolvidos. In: GAZOLLA, M.; SCHNEIDER, S. (Org.). Cadeias curtas e redes agroalimentares alternativas: negócios e mercados da agricultura familiar. Porto Alegre: Editora UFRGS, 2017. p. 175-194.

GRABOIS, J. et al. O papel da pequena produção na organização de um espaço periférico: o caso do noroeste fluminense. In: CARNEIRO, M. J. et al. (Org.). Campo aberto, o rural no Estado do Rio de Janeiro. Rio de Janeiro: Contracapa, 1998. p. 209-222.

INSTITUTO BRASILEIRO DE GEOGRAFIA E ESTATÍSTICA - IBGE. Cidades. Rio de Janeiro: IBGE, 2018.

INSTITUTO BRASILEIRO DE GEOGRAFIA E ESTATÍSTICA - IBGE. Estatística da pecuária do Instituto Brasileiro de Geografia e Estatística. Rio de Janeiro: IBGE, 2020.

INSTITUTO BRASILEIRO DE GEOGRAFIA E ESTATÍSTICA - IBGE. Produção Pecuária Municipal (PPM). Rio de Janeiro: IBGE, 2010.

INSTITUTO BRASILEIRO DE GEOGRAFIA E ESTATÍSTICA - IBGE. Produção Pecuária Municipal (PPM). Rio de Janeiro: IBGE, 2019. 
MADANÊLO, D. H. V. L.; MARAFON, G. O complexo agroindústria da pecuária leiteira no Estado do Rio de Janeiro. In: MARAFON, G. J.; RIBEIRO, M. A. (Org.). Revisitando o Território Fluminense II. Rio de Janeiro: Gramma, 2008. p. 7-16.

MARINHO, I. A Região Noroeste Fluminense e o Projeto Rio Rural: tendências e problemas da agricultura familiar. 2015. Dissertação (Mestrado em Geografia)-Universidade Estadual do Rio de Janeiro, São Gonçalo, 2015.

MARINHO, I. Processo de regionalização do noroeste fluminense. Revista Tamoios, São Gonçalo, v. 13, n. 2, p. 78-93, 2017.

PRADO JUNIOR, C. Formação do Brasil contemporâneo. São Paulo: Cia das Letras, 2011.

RIO DE JANEIRO. Decreto no 29.042 de 27 de agosto de 2001. Dispõe sobre o incentivo do governo do estado à produção de leite. Diário Oficial do Estado do Rio de Janeiro, Rio de Janeiro, 28 ago. 2001.

RIO DE JANEIRO. Rio Rural. 2008. Disponível em: <http://www.microbacias.rj.gov.br/pt/microbacias>. Acesso em: jun. 2018.

RIO DE JANEIRO. Decreto n. 41.765 de 20 de março de 2009. Programa de Incentivo do Governo do Estado à Produção de Leite. Diário Oficial do Estado do Rio de Janeiro, Rio de Janeiro, 23 mar. 2009.

RIO DE JANEIRO. Decreto n. ${ }^{\circ} 46.198$ de 18 de dezembro de 2017. Altera o decreto estadual n. ${ }^{\circ} 29.042$, de 27 de agosto de 2001, que dispõe sobre o incentivo do governo do estado à produção de leite. Diário Oficial do Estado do Rio de Janeiro, Rio de Janeiro, 19 dez. 2017, p. 1.

RIO RURAL. Projeto Desenvolvimento Rural Sustentável. Secretaria de Agricultura, Pecuária, Pesca e Abastecimento/Superintendência de Desenvolvimento Sustentável, 2009. p. 99.

SANTOS, E. V. M. As agroindústrias de lácteos no noroeste fluminense: panorama e desafios. In: ENANPEGE, 13., São Paulo. Anais... São Paulo: ANPEGE, 2019.

SANTOS, J. C. O sistema agroindustrial do leite na região de Presidente Prudente-SP. 2004. $200 \mathrm{f}$. Dissertação (Mestrado em Geografia)-Universidade Estadual Paulista, Presidente Prudente, 2004.

SCHMITZ, A. M.; SANTOS, R. A. A. A produção de leite na agricultura familiar do Sudoeste do Paraná e a participação das mulheres no processo produtivo. Terra Plural, Ponta Grossa, v. 7, n. 2, p. 339-355, 2013.

SCHNEIDER, S. Teoria social, agricultura familiar e pluriatividade. Revista Brasileira de Ciências Sociais, São Paulo, v. 18, n. 51, p. 99-121, 2003.

SILVA, A. C. P. Gestão e território: o caso da empresa Fleischmann \& Royal no noroeste fluminense. Revista Campo-Território: Revista de Geografia Agrária, Uberlândia, v. 2, n. 2-3, p. 53-75, 1997.

SILVA, A. C. P. As estratégias de modernização do espaço rural fluminense: técnica, planejamento e gestão no campo do Rio de Janeiro. Campo-Território: Revista de Geografia Agrária, Uberlândia, v. 1, n. 2, p. 92-122, 2006.

SISTEMA FIRJAN. Retratos regionais da região Noroeste. 2015.

SOUZA, S. O. et al. Diagnóstico participativo das propriedades leiteiras visando à Implantação das unidades de pesquisa participativa de pastoreio rotacionado silvipastoris em microbacias hidrográficas da região Noroeste Fluminense. Projeto Rio Rural/GEF - Pesquisa participativa. PESAGRO-RIO, set. 2014. p. 1-7.

VALVERDE, O. Geografia da pecuária no Brasil. Finisterra Revista Portuguesa de Geografia, Lisboa, v. 2, n. 4, 1967. Disponível em: <http://revistas.rcaap.pt/ finisterra/article/view/2524/2152\#>. Acesso em: 18 dez. 2020.

WANDERLEY, M. N. B. Agricultura familiar e Campesinato: rupturas e continuidade. Revista de Economia e Sociologia Rural, Brasília, v. 11, n. 2, p. 47, 2004.

WILKINSON, J. O setor de lácteos no Brasil no contexto da globalização. In: LIMA, E. N.; DELGADO, N. G.; MOREIRA, R. J. Mundo rural: configurações rural-urbanas - poderes e políticas. Rio de Janeiro: MAUAD, 2007. p. 353-371. 
Erika Vanessa Moreira Santos. Graduada, mestre e doutora em Geografia pela Universidade Estadual Paulista Júlio de Mesquita Filho (UNESP). Atualmente, é docente da Universidade Federal Fluminense, atuando no Departamento de Geografia de Campos (GRC) e no Programa de PósGraduação em Geografia (PPG). É membro do Núcleo de Estudos Rurais e Urbanos (NERU). Tem experiência na área de Geografia, com ênfase nos seguintes temas: rural-urbana, ruralidade, agricultura familiar, bairros rurais, agricultura urbana e geografia e gênero.

Samara Venina Simen de Azeredo Silva Chagas. Doutora em Engenharia e Ciências dos Materiais pela Universidade Estadual do Norte Fluminense Darcy Ribeiro (UENF) (2016). Mestre em Engenharia e Ciências dos Materiais pela UENF (2011). Graduada em Ciências Biológicas em (2007) e Licenciatura em Geografia pela Universidade Estadual do Rio de Janeiro (UERJ) (2019). Atualmente, é mestranda no Programa de Pós-Graduação em Geografia da Universidade Federal Fluminense e desenvolve pesquisa intitulada "Programa Rio Rural no município de Italva-RJ”, fazendo parte do Núcleo de Estudos Rurais e Urbanos (NERU).

Marco Túlio Morais Velasque Silva. Graduando em Geografia (Bacharelado) pela Universidade Federal Fluminense, em Campos dos Goytacazes (UFF/ Campos). É membro do Núcleo de Estudos Rurais e Urbanos (NERU). Atualmente, é bolsista de iniciação científica da FAPERJ e desenvolve pesquisa sobre "O rural no noroeste fluminense no contexto da agricultura familiar no século XXI”. 